\title{
O curso de Pedagogia e os retrocessos na legislação educacional: uma ofensiva às possibilidades de formação crítica ${ }^{1}$
}

\section{The Pedagogy course and the setbacks in the education legislation: an offensive on the likelihood of a critical training}

El curso de pedagogía y los reveses en la legislación educativa: una ofensiva a las posibilidades de la formación crítica

Antonia Alves Pereira Silva²

Maria Isabel Ramalho Ortigão ${ }^{3}$

DOI: http://dx.doi.org/10.20435/serie-estudos.v0i0.1487

\begin{abstract}
Resumo: Neste artigo, discutimos a formação de professores no Brasil com base na reflexão sobre a produção da política educacional, suas manifestações legais e seus impactos na formação de pedagogos. O texto tem por base uma pesquisa empírica realizada junto a estudantes e professores do curso de Pedagogia da Universidade Estadual do Piauí, conduzida com o objetivo de analisar a constituição de uma práxis como princípio epistemológico formativo. A pesquisa envolveu análise documental e entrevista individual e coletiva (grupo focal) com professores e estudantes. O arcabouço legal que atualmente subsidia a formação de pedagogos no país projeta, ainda que superficialmente, uma concepção de professor com possibilidade de atuação crítica na sua práxis profissional. Essa formação, contudo, encontra-se comprometida com a publicação da Resolução CNE/CP n. 02/19, que retoma uma perspectiva de formação docente centrada nas competências e provoca impactos significativos na organização do curso de Pedagogia. Respaldamos nossa discussão teórica no campo da política educacional de formação docente e na defesa de uma concepção de formação crítico-emancipatória.
\end{abstract}

Palavras-chave: formação docente; Pedagogia; perspectiva crítico-emancipatória.

\footnotetext{
${ }^{1}$ A pesquisa referenciada no texto contou com apoio da Fapepi e da Faperj.

2 Universidade Estadual do Piauí (Uespi), Teresina, Piauí, Brasil.

${ }^{3}$ Universidade do Estado do Rio de Janeiro (Uerj), Rio de Janeiro, RJ, Brasil.
} 
Abstract: The present article addresses teachers' training in Brazil based on a reflection about the production of public policies in education, their legal manifestations, and impacts on the training of Pedagogy professionals. The study is an empirical research carried out with students and professors of the Pedagogy Course of Piauí State University; it was conducted to assess the construction of practices as an epistemological education principle. The research was based on documental analysis and on one-on-one and group interviews (focal groups) with professors and students. We have argued that the legal framework that currently subsidizes the formation of professionals in Pedagogy in the country projects, although superficially, a concept of teachers who have the possibility to act in their professional practices. We have discussed that such a training, however, is compromised by the Resolution CNE/CP n. 02/2019, which brought back a professional training focused on competences and, consequently, has a strong impact on the organization of Pedagogy courses. We referenced our theoretical discussion on the education policy set for teachers' training and on the defense of a critical-emancipatory education concept.

Keywords: teachers training; Pedagogy; critical-emancipatory perspective.

Resumen: En este artículo, discutimos la formación de profesores en Brasil a partir de la reflexión sobre la producción de políticas educativas, sus manifestaciones legales y sus impactos en la formación de pedagogos. El texto se basa en una investigación empírica llevada a cabo con estudiantes y profesores del curso de Pedagogía de la Universidad Estatal de Piauí, realizada con el objetivo de analizar la constitución de una praxis como principio epistemológico formativo. La investigación incluyó análisis documentales y entrevistas individuales y colectivas (grupo focal) a profesores y estudiantes. Argumentamos que el marco jurídico que actualmente subvenciona la formación de pedagogos en el país proyecta, aunque superficialmente, una concepción del profesor con posibilidad de actuación crítica en su praxis profesional. Discutimos que esta formación, sin embargo, está comprometida con la publicación de la Resolución CNE/CP n. 02/2019, que retoma una perspectiva de formación docente centrada en las competencias y causa impactos significativos en la organización del curso de Pedagogía. Apoyamos nuestra discusión teórica sobre el campo de la política educativa de formación docente y en la defensa de una concepción de la formación crítico-emancipadora.

Palabras clave: formación docente; Pedagogía; perspectiva crítico-emancipadora.

\section{INTRODUÇÃO}

Nas últimas décadas, o discurso governamental acerca das políticas educacionais tem destacado a necessidade de melhoria na qualidade da educação oferecida nas escolas do país, sobretudo nas escolas públicas, em decorrência de seus resultados nas avaliações externas. Na esteira desse discurso, segue-se um conjunto de medidas que visam a promover reformas na educação que, supostamente, refletirão em melhorias na qualidade educacional. É o caso da mais recente aprovação de diretrizes curriculares para formação docente, que definiram uma base nacional comum para formação de professores em uma explícita submissão à Base Nacional Comum Curricular (BNCC) (BRASIL, 2017), 
de modo a viabilizar a execução das competências de aprendizagem previstas nesse documento.

Entendemos a formação de professores ofertada pelas instituições de ensino superior (IES) como um processo de dimensão social significativo, no qual esses profissionais possam colocar-se na condição de intelectuais, com responsabilidade e autonomia sobre o seu fazer pedagógico. Assim, defendemos que a formação de professores, em particular no curso de Pedagogia, deve pautar-se pelos princípios de unidade entre teoria e prática, configurada como práxis, e numa perspectiva crítico-emancipatória. Observamos que os documentos legais norteadores da formação nos cursos de Pedagogia, a Resolução do Conselho Nacional de Educação/Conselho Pleno (CNE/CP) n. 02/15 e a Resolução CNE/CP n. 01/06, que promovem experiências formativas curriculares significativas no campo da docência, permitem questionar a implementação de novas diretrizes de formação docente.

Neste artigo, discutimos a formação de professores com base na experiência do curso de Pedagogia da Universidade Estadual do Piauí (Uespi). Especificamente, trazemos aqui os resultados de uma investigação que objetivou analisar o currículo do curso de Pedagogia à luz dos seus elementos curriculares, identificando processos e práticas que, na percepção dos sujeitos, se desenvolvem numa perspectiva de unidade teórico-prática. Para este artigo, discutimos dados relativos à concepção de formação no curso baseada na percepção de estudantes e professores.

O texto está organizado em quatro seções além desta introdução. Na continuidade, discutimos política de formação docente, com foco na Pedagogia, assumindo uma concepção crítico-emancipatória de formação. Em seguida, apresentamos o contexto em que a pesquisa foi conduzida e discutimos os resultados alcançados. Concluímos com uma reflexão sobre os impactos da Resolução CNE/ CP n. 02/19 (BRASIL, 2019) para o curso de Pedagogia e apresentamos nossas considerações finais.

\section{POLÍTICA DE FORMAÇÃO DOCENTE E DE PEDAGOGIA}

A implementação de políticas curriculares não é algo que ocorre por decreto, mas requer o apoio dos professores, que são os agentes atuantes nas políticas educacionais. As políticas que visam à alteração dos currículos escolares, a exemplo dos Parâmetros Curriculares Nacionais (PCN) nos anos 1990 e, mais recentemente, 
da Base Nacional Comum Curricular (BNCC) (BRASIL, 2017), atuam em paralelo às políticas que regulamentam a formação docente.

Freitas (2007), ao analisar essa dinâmica na educação brasileira, menciona que a política de formação docente do País configurada na década de 1990, no âmbito das reformas do Estado, visava a atender às recomendações dos organismos internacionais. À época, a autora denunciava que as propostas daquela política não somente não resolveriam os problemas da formação como contribuiriam para sua desprofissionalização, ao apontar, por exemplo, a diversidade e a flexibilidade no modo de formação, a ênfase nas competências e em uma política de formação a distância empreendida pelo Governo Federal.

Candau (2013) observa que as reformas educacionais na América Latina, incluindo as de formação docente, estão pautadas na narrativa de melhoria da qualidade da educação que conduz a uma espécie de consenso reformista orientado por técnicos internacionais

[...] com base em enfoques economicistas e centrados no tema da produtividade e da necessidade de gerar reformas educativas que favoreçam a inserção dos respectivos países na lógica da competitividade. (CANDAU, 2013, p. 32).

No Brasil, essas características refletem uma concepção de formação de professores que permeou as reformas da década de 1990, com a aprovação da LDB (Lei n. 9.394/96) e de um conjunto de documentos oficiais regulamentando essa lei. Em relação à política de formação de professores, o auge foi a aprovação das Diretrizes Curriculares para Formação de Professores da Educação Básica em Nível Superior, por meio da Resolução CNE/CP n. 01/02 (BRASIL, 2002), que trazia uma concepção de professor sintonizada com as demandas do mercado, projetando um docente mais voltado para o saber-fazer, comprometido com as questões do ensino e da sala da aula sem relacionar esse processo aos fatores macrossociais que o condicionam.

A concepção de formação de professor advinda dessa resolução é criticada por diversos autores, como Freitas (2007), Scheibe (2002), Veiga e Viana (2012), Gatti, Barreto e André (2011), entre outros. Todos eles observam que aqueles documentos traziam como ideia central a formação como dimensão técnica da docência, uma visão dicotomizada da relação entre teoria e prática, que separa trabalho intelectual e trabalho prático e, consequentemente, trabalho e educação. 
O contraponto legal a essa concepção técnica de formação de professores veio com a Resolução CNE/CP n. 02/15, que aprovou novas Diretrizes Curriculares Nacionais para Formação Inicial e Continuada de Professores. Essa resolução resultou de um longo processo de construção e foi pautada na reflexão histórica sobre o processo de formação docente, considerando um amplo debate com entidades específicas da sociedade civil. Nesse sentido, ela é marcada por um processo de construção democrático. De acordo com o professor Luiz Fernandes Dourado, relator do texto das Diretrizes no CNE, elas trazem uma concepção de formação docente que respeita a luta histórica da categoria, que procura articular formação inicial e continuada, com base em uma organicidade entre as instituições formadoras e a educação básica e numa intrínseca relação entre graduação e pós-graduação (DOURADO, 2015).

A Resolução CNE/CP n. 02/15 reafirma princípios formativos construídos pelas diversas entidades educacionais e científicas de luta pela educação e com foco na formação docente, a exemplo da Associação Nacional para Formação dos Profissionais em Educação (Anfope), Associação Nacional de Pesquisa e PósGraduação em Educação (ANPEd), Fórum de Diretores de Faculdades e Centros de Educação das Universidades Públicas Brasileiras (Forumdir), Associação Nacional de Administradores Educacionais (Anpae) e Confederação Nacional dos Trabalhadores em Educação (CNTE).

Entre esses princípios, está a defesa de uma base comum nacional para formação de todos os profissionais da Educação. Essa ideia, construída no âmbito das diversas entidades, posteriormente sistematizada pela Anfope, constitui-se de: sólida formação teórica e interdisciplinar; unidade teoria-prática; trabalho coletivo e interdisciplinar; compromisso social e valorização profissional; gestão democrática e avaliação; e regulação dos cursos de formação (DOURADO, 2015).

A Resolução CNE/CP n. 02/15 apresenta uma concepção de educação como sendo um processo amplo, formativo e emancipatório, que se desenvolve nos diversos espaços sociais de forma inter-relacionada. Do mesmo modo, compreende a docência como processo metódico complexo que se realiza com base em um conjunto de conhecimentos interdisciplinares, o que caracteriza a ação docente no espectro de dimensões técnicas, políticas, éticas, estéticas e caracterizadas por sólida formação envolvendo conteúdos e metodologias diversas (BRASIL, 2015). 
Essa compreensão imprime um sentido basilar à formação docente, que passa a priorizar conhecimentos (BAZZO; SCHEIBE, 2019), dada a complexidade em que se desenvolve o processo educacional e a necessidade de profissionais capazes de saber lidar com a diversidade e a imprevisibilidade da prática educacional. Distingue-se, pois, da visão de formação constante na Resolução de 2002, que enfatizava a aquisição de competências pragmáticas a serem executadas em contextos particularizados. Outro ponto ressaltado como inovador é a concepção integrada entre formação inicial e continuada, bem como a articulação entre formação e carreira docente. Este último aspecto resulta de uma reivindicação antiga da categoria de educadores, que, ao vincular a discussão da formação à carreira, viabiliza uma maior valorização profissional.

A Resolução de 2015, nesse sentido, pode ser considerada inovadora e ousada em termos de pensar a formação de professores. Conforme Dourado, as Diretrizes de 2015 defendem

[...] a institucionalização de um projeto de formação pelas instituições de Educação Superior, priorizando as universidades, por meio da efetiva articulação dessas IES com os entes federados, seus sistemas e redes, instituições de educação superior e instituições de educação básica, sem descurar da efetiva participação dos fóruns permanentes de formação e demais instâncias como conselhos nacional, distrital, estaduais e municipais e respectivos fóruns. (DOURADO, 2015, p. 315).

A implementação da Resolução de 2015, todavia, prevista para dois anos, enfrentou diversos obstáculos, em especial a partir do impeachment da presidenta Dilma Rousseff, culminando na mudança do chefe do Governo Federal, em 2016. Algumas instituições de ensino procuraram reformular seus currículos seguindo as orientações contidas na Resolução CNE/CP n. 02/15. Após a aprovação da BNCC do Ensino Médio, foi dado como certo que a Resolução de 2015 seria substituída por novas diretrizes de formação docente, o que ocorreu em 2019. Retomaremos essa discussão posteriormente.

O norteamento legal advindo da Resolução CNE/CP n. 01/06, que definiu as Diretrizes Curriculares Nacionais de Pedagogia (DCNP), também traz uma concepção de formação oriunda dos debates com as associações. De acordo com Scheibe (2007), a proposta das Diretrizes para Pedagogia, aprovada em 2006 pelo CNE, contemplou, sobretudo, as sugestões de entidades com protagonismo nas discussões sobre a formação de professores, entre as quais Anfope, Anped, Forumdir e Anpae. 
O texto das DCNP carrega ideias advindas do campo progressista da educação, ao contemplar a formação integrada - docência e gestão escolar - e basear-se na noção ampliada de docência, de prática educativa como processo complexo, multirreferencial, que extrapola as dimensões da sala de aula. Essa concepção está fundamentada numa perspectiva crítica da educação que, do ponto de vista epistemológico, visa a superar uma fragmentação que coloca teoria e prática em posições antagônicas.

Com essa perspectiva de formação e levando em conta assertivas da visão crítica e pós-crítica na definição do seu perfil, pressupõe-se que elas dão fundamento, em termos da relação uno/plural, para se contrapor à forma de organizar institucionalmente o curso de Pedagogia, sob a tradução de cursos separados (bacharelado e licenciatura ou similares) no interior da universidade. (AGUIAR; MELO, 2005, p. 122).

No que se refere a princípios formativos gerais, as Diretrizes de Pedagogia orientam-se pelas defesas de uma sólida formação teórica e interdisciplinar e de unidade entre teoria e prática. A Resolução CNE/CP n. 01/06 determina que os estudos de formação nos cursos de Pedagogia sejam realizados de forma teórico-prática (BRASIL, 2006). O Parecer CNE/CP n. 05/05 (BRASIL, 2005), que trata das DCNP, destaca o trabalho do pedagogo como aquele que se realiza em uma práxis social. Tais indicações, aliadas a outras presentes na Resolução e no Parecer, a exemplo de uma percepção de educação numa perspectiva sócio-histórica, projetam a possibilidade de formação de profissionais comprometidos com os princípios de uma educação democrática.

É necessário mencionar que as DCNP são resultado de um conjunto de disputas de diferentes percepções acerca da formação do pedagogo. Seu texto, como toda política, não resulta de consenso. Entretanto sua aprovação representou um marco na história do curso, que, pela primeira vez, passa a ter Diretrizes Curriculares, gerando grandes expectativas quanto às orientações na elaboração dos currículos das IES.

\section{CONCEPÇÃO DE FORMAÇÃO CRÍTICO-EMANCIPATÓRIA}

Como discutido antes, verifica-se que tanto a Resolução CNE/CP 02/15 quanto as DCNP possuem discursos articulados com perspectivas progressistas no campo teórico da Educação. Defendemos que pensar a formação de professores 
a partir desses referenciais implica colocar-se de antemão diante de alguns questionamentos, tais como: que sociedade se quer formar? Que tipo de escola se deseja? Projetar identidades docentes está intrinsecamente vinculado a um projeto de sociedade. Mesmo que essas identidades e projetos não se concretizem.

Giroux (1997) afirma que a reflexão sobre o papel do professor na sociedade atual precisa vincular-se à reflexão acerca do propósito social da escola, que, para ele, deve ser considerada como espaço democrático no qual deve ser fortalecido tanto o self quanto o social, e os estudantes tenham fortalecidas suas habilidades para viver em autênticas democracias. Assim,

[...] em vez de definir as escolas como extensões do local de trabalho ou como instituições de linha de frente na batalha dos mercados internacionais e competição estrangeira, as escolas como esferas públicas democráticas são construídas em torno de formas de investigação crítica que dignificam o diálogo significativo e a atividade humana. (GIROUX, 1997, p. 28).

Partindo dessa prerrogativa, entendemos o trabalho do professor numa dimensão de atuação que, sem negligenciar a formação cognitiva dos estudantes, seja capaz de auxiliar na compreensão das condições sócio-históricas que os condicionam enquanto sujeitos; o conhecimento das próprias condições do passado e do presente auxilia na reflexão das possibilidades futuras. Assim, o professor é um crítico que atua contribuindo para o processo de reconhecimento e construção de identidades subjetivas e coletivas, capaz de contribuir com os processos de emancipação dos sujeitos.

Freitas (2007) trata desse tema ressaltando a necessidade de pensar uma sociedade na qual as desigualdades sociais sejam continuamente enfrentadas e superadas; em que os indivíduos sejam reconhecidos em suas diferenças e particularidades, mas também como membros de um grupo; uma sociedade em que os indivíduos tenham garantias de participação nos bens socialmente produzidos, independentemente de classe, raça, sexo, religião e cultura; uma sociedade mais justa, menos desigual.

Giroux (1997) concebe os professores como intelectuais transformadores atuando nas escolas, concebidas por ele como esferas públicas democráticas. Ou seja, percebê-las como espaço cultural e de luta política, não apenas de veiculação de saberes científicos, uma visão em que o trabalho do professor se contrapõe àquela que o define como meramente técnico. 
A formação desse profissional, na visão de Giroux (1997), requer mudanças nas instituições formadoras de professores, a fim de que sua formação seja pensada como um projeto político amplo ou luta social geral. Para ele, instituições precisam ser repensadas como sendo esferas públicas, com programas em que os professores sejam formados como intelectuais transformadores, aptos a submeter à crítica radical aspectos como a natureza da atividade docente, a vida escolar cotidiana e a finalidade da escolarização.

A capacidade de desenvolvimento de uma reflexão radical, que para Giroux (1997) pode ser aprendida no processo de formação, permitirá ao professor agir como intelectual transformador, pois ele submete cotidianamente a própria prática à análise, o que implica a responsabilidade de refletir sobre o que ensina, como deve ensinar e quais são as metas mais amplas pelas quais está lutando. Porém não o faz individualmente, numa atitude isolada, mas na interação com seus pares. Nesse sentido, é possível vislumbrar a criação de uma pedagogia que o autor chama de "pedagogia da possibilidade", um agir contra-hegemônico no sentido gramsciano.

O pensamento crítico de Henri Giroux teve ampla repercussão no Brasil, influenciando teóricos da Educação e entidades que discutem a formação de professores. A Anfope, nesse sentido, defende a ideia de professor comprometido com os referenciais de uma formação crítico-emancipatória feita com base em uma perspectiva sócio-histórica da Educação, situando as lutas históricas dos trabalhadores em Educação, a educação como socialmente contextualizada e o professor com compromisso social (ANFOPE, 2016).

Entre os diversos autores que corroboram a concepção formativa defendida pela Anfope, Freitas (2007, p. 1.220) defende que a formação sócio-histórica e a base comum nacional criam condições para a formação unitária dos educadores, pelo caráter geral, científico e multifacético que essas formulações carregam.

Na mesma linha, Silva $(2011 ; 2017)$ defende a formação docente crítica-emancipadora baseada na concepção dialética de Marx e Gramsci. Ela argumenta com a necessidade de resgate de categorias básicas da dialética que permitam construir um projeto de formação docente numa perspectiva efetivamente crítico-emancipadora. A autora tem defendido a formação comprometida com a emancipação relacionada aos aspectos sociais, políticos, econômicos e culturais, em que autonomia e liberdade são os marcos centrais da formação. 
Entendemos, assim, que a noção de emancipação defendida por Silva (2017) extrapola a dimensão do individualismo e alcança um sentido de coletividade; ela toma o sentido de uma práxis social viabilizada com auxílio da práxis educativa. Acreditamos que, nesse sentido, há uma aproximação das ideias de Silva com as defendidas por Freire (1987), em especial no que tange à defesa das relações entre os sujeitos do processo educativo que precisam ser postas numa perspectiva de diálogo. Também identificamos aproximações com as ideias de Giroux (1997), quando ela defende que os saberes científicos e culturais integrem a formação dos sujeitos.

Assim, compreendemos que a formação de professores visando à qualidade do trabalho docente na perspectiva de inserção social dos estudantes, para além de uma preparação técnica, deve ser realizada fora do modelo da racionalidade técnica e em sintonia com a concepção crítico-emancipatória, mas entendendo a emancipação como processualidade e que se realiza em diferentes níveis: o político, o social, o cultural, o econômico e o epistemológico (SANTOS, 2013). Na continuidade, apresentamos os resultados da pesquisa mencionada na introdução.

\section{EXPECTATIVAS DE UMA FORMAÇÃO CRÍTICA - O CURSO DE PEDAGOGIA DA UESPI}

Como dito na introdução, este texto foi construído tendo por base pesquisa empírica desenvolvida na Universidade Estadual do Piauí (Uespi) e teve como objetivo geral analisar o currículo do curso de Pedagogia à luz dos seus elementos curriculares, identificando processos e práticas que, na percepção de professores e estudantes, se desenvolvem numa perspectiva de construção da dimensão teórico-prática.

A Uespi é uma instituição de ensino superior multicampi, criada em 1986, com sede na capital do estado. Atualmente, possui 12 campi e 12 núcleos, além de 11 polos de educação a distância. O curso de Pedagogia funciona em todos os campi. Nossa investigação focou exclusivamente o curso de Pedagogia do campus Torquato Neto, situado em Teresina.

A pesquisa considerou aspectos macrossociais e microcontextuais (LOPES, 2006; BRANDÃO, 2001) na produção do conhecimento, numa perspectiva dialética materialista; envolveu: a) análise de documentos legais que subsidiam a formação em Pedagogia e do projeto pedagógico do curso da Uespi; b) entrevistas com oito professores responsáveis pelas disciplinas do segundo ao nono períodos, 
pertencentes aos núcleos de Fundamentos da Educação, Disciplinas Pedagógicas e Estágio Supervisionado; e c) grupo focal envolvendo 48 estudantes matriculados nessas disciplinas.

Para o propósito deste texto e dada a limitação em número de páginas, discutimos aqui a concepção de profissional formado no curso com base na fala dos professores e dos estudantes. Tomando como referência a concepção docente na perspectiva crítico-emancipatória, buscamos saber como as professoras percebiam o tipo de profissional pedagogo formado no curso; e se essa formação se caracterizaria mais por uma abordagem tecnicista ou crítica em relação à Educação.

Das oito docentes entrevistadas, três apontaram tanto uma formação voltada para a dimensão técnica quanto para a crítica, e cinco consideram que o curso forma numa concepção crítica da Educação; uma das professoras usou a terminologia "crítico-reflexiva".

Ao mencionar a concepção crítica do pedagogo egresso do curso, as professoras justificaram suas respostas principalmente em relação ao conjunto de disciplinas da estrutura do curso, às práticas realizadas pelos alunos durante as atividades nas escolas, à postura madura de muitos estudantes ao buscar aprofundar o estudo de questões que surgem em sala de aula, à qualidade dos trabalhos de conclusão (TCC) realizados com temas de pesquisa que mostram um olhar amplo sobre a problemática da Educação, à capacidade de percepção da realidade educacional com suas problemáticas, além do êxito dos alunos nos concursos realizados pelo município. As falas a seguir ilustram essas ideias.

As disciplinas que nós temos aqui proporcionam ao aluno o refletir politicamente sobre as questões sociais, sobre as questões que eles vão encontrar dentro da escola, os problemas sociais. (Profa. Tatiana) 4 .

A estrutura do projeto; e eu vejo na prática, nos nossos encontros que os alunos colocam no nosso dia a dia, nas discussões eles começam a ter uma postura bem crítica. Temos alunos muito atuantes nessas perspectivas de movimento de atuação, reivindicações de direitos, de lutas, de perceber a educação no que deve mudar. (Profa. Ana Maria).

O professor formado na perspectiva crítica da educação deve estar comprometido com os princípios de democratização, justiça social e defesa da escola

\footnotetext{
${ }^{4}$ As professoras foram identificadas por nomes fictícios; os estudantes, por numeração e indicação do bloco no qual estavam matriculados (Exemplo: E1B2 = Estudante 1, Bloco 2).
} 
pública. Por isso mesmo, como intelectuais, "precisam desenvolver um discurso que una a linguagem da crítica e a linguagem da possibilidade, de forma que os educadores sociais reconheçam que podem promover mudanças" (GIROUX, 1997, p. 161). Os dados obtidos junto às professoras destacam a predominância de uma dimensão sociopolítica e humana da formação docente (CANDAU, 2011), o que nos leva a deduzir que há um processo formativo direcionado à perspectiva crítico-emancipatória.

Não obstante, há professoras que percebem forte presença de um fazer técnico na formação. Elas evidenciam uma preocupação com uma possível modelagem do pedagogo baseada numa concepção mais pragmática que permeia o ambiente escolar, uma concepção profissional forjada na pressão dos contextos escolares. Esse dado nos faz refletir acerca do impacto dos professores da universidade no processo de formação, posto em xeque quando os estudantes intensificam sua presença no ambiente escolar. Há nessa questão uma contradição que é inerente ao processo de formação docente, que é complexo, multidimensional (CANDAU, 2011; VEIGA; VIANA, 2012), contingencial e disputado (DIAS, 2008) e que está em íntima relação com as contradições da sociedade em que se desenvolve.

No diálogo com os estudantes, um dos objetivos foi perceber a compreensão que tinham em relação ao próprio objeto de trabalho e seu papel em relação a ele, bem como o conhecimento da realidade de atuação. A expressão desse posicionamento permite inferir uma concepção de educador e uma compreensão de práxis. De acordo com Vázquez (2011), a práxis exige dos sujeitos o conhecimento sobre o seu objeto de trabalho e de sua função em relação a ele no sentido da transformação social.

Nas entrevistas com os alunos, realizadas por meio de grupo focal, procuramos analisar sua compreensão sobre a função da Educação na sociedade e de seu papel como pedagogos, especialmente em relação ao planejamento da prática educativa enquanto atividade humanizadora voltada para a transformação social. Buscamos também conhecer suas percepções sobre o impacto do processo formativo sobre si mesmos na condição de sujeitos.

No que se refere à função da Educação e ao papel do pedagogo, as falas dos estudantes anunciam uma compreensão da educação coerente com o sentido amplo da palavra. São explanadas referências de que a Educação tem como 
O curso de Pedagogia e os retrocessos na legislação educacional: uma ofensiva às possibilidades de formação crítica

finalidade formar o cidadão crítico; que o professor deve ser o multiplicador de conhecimentos significativos que sejam capazes de transformar a realidade. A noção de que a Educação cumpre uma função humanizadora na sociedade foi bastante presente em suas falas, bem como a compreensão do papel do professor na transformação da realidade.

O professor tem o papel de educar, então ele tem essa formação de ir bem além; a questão de formar pessoas, construir seres humanos críticos; dele construir a criticidade da pessoa para que ela futuramente possa ser independente. (E7B6).

Então eu acho que a gente tem aquela capacidade de ser mais empático; de compreender mais a questão humana, porque a gente tem um processo que é de estar estudando não só as crianças, mas o ser humano. (E1B6).

Ao falarem sobre os efeitos do processo formativo sobre si, os estudantes enfatizaram que atualmente são pessoas diferentes de quando ingressaram no curso. Em suas falas, foram ressaltadas mudanças tanto no que se refere aos aspectos da cognição quanto à própria personalidade, ao salientarem, por exemplo, que eram pessoas mais individualistas e que no curso aprenderam a colaborar, compartilhar, ressignificar o que representa ser professor.

Quando comecei na prática, a vivenciar aquilo, eu me tornei uma pessoa mais paciente [...]. Eu sou muito crítica com pessoas que trabalham na Educação Infantil, trabalham com crianças e não têm paciência para ver as crianças como crianças, de saber que elas estão ali para aprender, para perguntar, para aprontar e você tem que saber como conduzir aquilo ali. (E5B7).

Segundo Vázquez (2011), não existe práxis sem conhecimento da finalidade da atividade exercida, tampouco sem perspectiva de transformação inerente a ela. As falas aqui mostradas se articulam em torno de um discurso que permite inferir que os estudantes possuem conhecimento da finalidade da prática educativa e de seu papel como agentes que devem atuar contribuindo para a transformação da sociedade e para o processo de emancipação dos sujeitos via conhecimento. Na perspectiva da práxis dialética, essa transformação precisa ocorrer também na esfera individual, no reconhecimento dos sujeitos acerca do seu papel social.

Os depoimentos, no seu conjunto, remetem à valorização da função da Educação e do papel do professor na sociedade. Alguns chegam a assumir um tom quase salvacionista em relação à Educação e ao professor, o que revelaria 
uma visão acrítica em relação à Educação. Porém predomina entre os estudantes uma postura de que a Educação sozinha não "salva" a sociedade.

Mas é interessante que a gente sempre lembre que não é somente a educação sozinha; essa educação deve estar junto com todas as outras instituições da sociedade para que só assim o indivíduo possa ter a sua formação completa. (E8B6).

Essa fala revela capacidade de análise crítica quanto ao objeto do próprio trabalho - a Educação -, sem, entretanto, deixar de valorizá-la como parte do processo de transformação social. Com isso, vai ao encontro do pensamento de Freire (1987) ao ser dito que a educação sozinha não transforma o mundo, tampouco sem ela isso acontecerá.

Como dito acima, indagamos os estudantes sobre como percebiam a contribuição do conjunto das disciplinas e práticas curriculares às realidades de atuações e funções que têm ou terão após a conclusão do curso. Acreditamos que o processo formativo precisa favorecer o debate acerca da escola, sua função social, histórica, os elementos contextuais que a definem e seus sujeitos e práticas, entre outros. Trata-se de um tipo de conhecimento que é teórico-prático e pode ocorrer de diversas formas, com conteúdos e autores variados, observações de situações reais, relatos de experiências para análise, realização de pequenos projetos etc. Esse conjunto de reflexões, cremos, subsidia o aluno, futuro professor, na análise do real, tendo em mente uma realidade desejada, que se queira transformar.

Para os estudantes, a formação permite o conhecimento acerca da realidade. Eles ressaltam, porém, que algumas questões não são suficientemente abordadas. Há realidades que eles só percebem quando chegam às escolas, tais como questões sobre drogas e violências, em especial as decorrentes do tráfico de drogas.

Eu vejo que não está sendo discutido como deveria. Muitas vezes a gente tá trabalhando aqui, estudando um tema, aí nas observações na escola nos deparamos com situações que realmente nunca imaginávamos como, por exemplo, crianças que têm pais são usuários de drogas, são traficantes, eles mesmos vendem drogas; situações assim do tipo que nós não esperávamos encontrar [...] poderia ser mais discutido. (E2B6).

As falas revelam o caráter da imprevisibilidade inerente à educação e de uma realidade educacional que se mostra complexa, dinâmica e de difícil apropriação. A esse respeito, Silva (2017) salienta que o trabalho com a epistemologia da práxis oferece elementos para conhecimento e análise da realidade e suas contradições. 
Alerta, contudo, que é necessário compreender que a realidade não se constitui em uma presença objetiva e monolítica. Nesse aspecto, pensamos ser necessário frisar a impossibilidade de apropriação da realidade como totalidade. Acreditamos ser imprescindivel que as estratégias de ensino enfatizem a relação entre o particular e o universal, explicitando que na realidade educacional manifestam-se os elementos da realidade social ampla.

Com base nos dados apresentados, é possível afirmar que, no que tange à concepção de formação, o currículo da Uespi tem norteado uma perspectiva crítica da educação. Ao fazer essa consideração, não estamos colocando-a em termos de verdade materializada, tampouco compreendemos que a formação docente seja resultado apenas do que um currículo formalizado possa expressar. Estamos ressaltando que existem indicativos apontados pelos sujeitos de que há uma formação em curso que possibilita, por exemplo, compreender a Educação num sentido amplo e que seu papel na sociedade é contribuir para a sua transformação.

Partindo desse ponto, queremos retornar à política de formação do pedagogo que, até o momento, vem norteando tal formação. Consideramos que toda política é recontextualizada (BERNSTEIN, 1996) e que os espaços de produção da política curricular docente nas últimas décadas têm permitido, de algum modo, autonomia aos sujeitos das instituições para novas e necessárias recontextualizações. Nosso entendimento é de que o cenário criado pelos governos pós-golpe de 2016 tem atuado no sentido de minimizar as possiblidades de reelaboração de políticas e, simultaneamente, projetar, em termos legais, modelos de formação docente que confrontam os avanços conquistados até o momento, refletindo-se na aprovação abrupta da Resolução CNE/CP n. 02/19, aspecto que passaremos a discutir.

\section{RESOLUÇÃO CNE/CP N. 02/19 - RETROCESSOS NA FORMAÇÃO DE PEDAGOGOS}

Dissemos anteriormente que a Resolução CNE/CP n. 02/15 sofreu percalços quanto à sua efetiva implementação após o impeachment da presidenta Dilma Rousseff e, especialmente, após a aprovação da BNCC, uma vez que o discurso na esfera governamental passa a ser a produção de novas Diretrizes de formação docente em consonância com a Base. Bazzo e Scheibe (2019) avaliam que as sucessivas prorrogações no prazo de implementação da Resolução tinham por objetivo viabilizar novas Diretrizes que subsumissem a formação docente à BNCC. 
Esse cenário foi agravado com o resultado das eleições de 2018 e a chegada ao poder de um governo conservador de extrema direita. Nessa conjuntura, o discurso de uma base nacional comum para a formação docente se intensificou e sua produção ocorreu distante dos institutos democráticos da sociedade civil.

Farias (2019) salienta que a rapidez com que a proposta se desenhou no âmbito do governo e a ausência de informações para sociedade civil sobre o conteúdo dessa proposta caracterizaram o que chamou de contrarreforma,

processo encaminhado, desde o impeachment do governo de Dilma Rousseff, de maneira intempestiva e rompendo com processos coletivos de discussão e negociação legalmente constituídos, o que se materializou por interesses diversos, comprometendo aspectos e decisões democráticas, situação essa que é evidenciada, por exemplo, na própria elaboração e discussão da Base Nacional Comum Curricular (BNCC). (FARIAS, 2019, p. 157).

Ao término do ano de 2019, precisamente no dia 20 de dezembro, diversos setores da educação foram surpreendidos com a publicação da Resolução CNE/ CP n. 02/19, definindo Diretrizes Curriculares Nacionais para a Formação Inicial de Professores para a Educação Básica e instituindo a Base Nacional Comum para a Formação Inicial de Professores da Educação Básica (BNC-Formação). Sem discussão com as entidades, IES ou com a sociedade, e de forma impositiva, o documento passa a nortear processos de elaboração e reformulação curricular no País.

A leitura da resolução permite inferir, de imediato, seu propósito de projetar a formação do professor articulada à BNCC, ou seja, a leitura da Resolução CNE/CP n. 02/19 (BNC-Formação) leva à percepção de que esse documento foi elaborado como forma de viabilizar, na prática escolar, o cumprimento da BNCC. Nela é enfatizada a formação por competências, precisamente aquelas que supostamente, ao serem adquiridas durante a formação, permitirão aos futuros docentes a realização, junto aos alunos, das competências curriculares previstas na BNCC. Esse aspecto evidencia uma concepção de formação que enfatiza a dimensão técnica da profissão docente, um retorno aos ditames da Resolução de 2002, com o adicional do papel do professor como estratégia do Estado para implementação de uma política de padronização curricular.

Outro aspecto perceptível no documento é que, na relação entre teoria e prática, a dimensão prática ganha centralidade e revela uma vinculação da 
compreensão de competências enquanto técnica. Esse entendimento pode ser ressaltado pelo fato de que, no texto da BNC-Formação, não há referência à formação docente como processo de aquisição e construção de conhecimentos, mas de competências que viabilizam habilidades práticas.

Evidencia-se também que a nova resolução é desprovida de vinculação com a discussão histórica em torno da formação de professores realizada pelas entidades representativas de classe. Sob esse aspecto, contrapõe-se à Resolução CNE/CP n. 02/15, que apresentava um texto resultante de uma discussão histórica e política acerca da formação docente, vinculando formação e carreira docente como estratégia de valorização profissional. Esses elementos inexistem no documento de 2019. Tampouco esse novo documento resgata os aspectos da Base Nacional Comum presentes no documento de 2015.

No que se refere à Pedagogia, a Resolução de 2019 ignora toda a discussão histórica em relação ao curso que, a despeito das disputas existentes, resultou em um norteamento da formação coerente com as expectativas de entidades e setores progressistas da educação. A resolução atual reduz a Pedagogia ao magistério ao prever cursos separados para formação docente e para funções de gestão educacional, em contraposição à ideia de uma formação ampla e integrada do pedagogo, formação essa que derivou de uma concepção epistemológica de formação que situa teoria e prática como dimensões unitárias do fazer docente.

Ressalte-se que o modo como está posta essa questão na BNC-Formação permite o resgate de um modelo de formação na Pedagogia superado e bastante criticado - o das habilitações, que remontam à década de 1970. Esse modelo comprometeu por décadas a discussão da identidade profissional e fragmentou o trabalho docente no contexto das escolas.

Igualmente preocupante é a proposição de cursos separados de docência para educação infantil e anos iniciais do ensino fundamental. Ora, a fundamentação constante nas DCNP compreende a Educação como processo amplo que se realiza como resultado da interação entre instituições e saberes diversificados. A noção de formação de professores como posta na nova resolução fragiliza a Educação como fenômeno amplo, diversificado, multirreferencial, e fragmenta ainda mais a realização do trabalho no contexto escolar.

Assim, a BNC-Formação representa, a nosso ver, um retrocesso e um ataque brutal ao curso de Pedagogia, à sua história e às suas diretrizes, construídas 
de forma democrática e participativa. Representa ainda um ataque às práticas formativas que vêm sendo realizadas País afora e que visam a contribuir para a formação de um profissional com visão crítica da Educação, como defendido neste texto, com apoio de diversos autores e clamado nas falas dos estudantes e professores que participaram da pesquisa.

Entendemos que as DCNP até necessitem de revisão, dado o tempo histórico decorrido de sua aprovação. Entretanto, defendemos que isso deva ocorrer como resultado de um processo de avaliação e com a participação das entidades educativas em um modelo democrático.

\section{CONSIDERAÇÕES FINAIS}

A questão basilar que nos move à reflexão neste artigo é a compreensão da Educação como direito social e sua inexorável relevância como fator de contribuição para redução das desigualdades sociais. Para tanto, é necessário que ela seja pensada como política pública que amplie essa funcionalidade, e não como elemento de restrição. Nessa lógica, insere-se a política de formação docente. Entendemos que a formação de professores extrapola a aquisição de competências e habilidades numa perspectiva de técnica para execução de determinado currículo padronizado.

Nesse sentido, avaliamos que a produção de política de formação docente nos últimos anos, notadamente a BNCC e a BNC-Formação, caminha em direção oposta à noção de Educação em sentido amplo e pleno e não favorece a formação de profissionais com condições de exercício da profissão para atuar de forma crítica. Visa tão-somente a treiná-los para o exercício de competências a serem posteriormente medidas, avaliadas por sistemas de avaliação externa com foco apenas nos resultados.

A pesquisa empírica sobre o curso de Pedagogia da Uespi indicou que, no processo de formação, predomina uma concepção crítica do pedagogo, com uma compreensão da Educação voltada para a transformação social, além de relativo conhecimento da realidade educacional que permite, segundo os discentes, ser capaz de intervir na realidade educativa. Portanto o norteamento legal do curso, por meio de suas diretrizes, tem contribuído para a formação crítico-emancipatória desse profissional. A atual BCN-Formação despreza toda a história desse curso, suas DCNs e o papel dos diversos protagonistas do País nessa história, tanto em 
termos legais (contribuindo na reflexão sobre as DCNP) como em termos político-pedagógicos na elaboração e reelaboração de propostas curriculares e formação de novos profissionais. Destacamos ainda, com mais intensidade, a prática de milhares de pedagogos pelas escolas deste País, os quais atuam de forma crítica, contribuindo para a formação cognitiva e cidadã de milhões de crianças.

É imperativo, pois, questionar o caráter autoritário e retrógrado da BNCFormação e reafirmar a necessidade de formação de professores e pedagogos numa perspectiva crítico-emancipatória da Educação, o que nos induz a buscar pensar, juntamente das diversas entidades de luta, formas de resistência a tal documento.

\section{REFERÊNCIAS}

AGUIAR, Márcia Angela Silva; MELO, Maria de Oliveira. Pedagogia e as diretrizes curriculares do curso de Pedagogia: polêmicas e controvérsias. Revista Linhas Críticas, Brasília, v. 11, 2005. Disponível em: https://periodicos.unb.br/index.php/. Acesso em: 1 ㅇ maio 2019.

ASSOCIAÇÃO NACIONAL PELA FORMAÇÃO DOS PROFISSIONAIS DA EDUCAÇÃO [ANFOPE]. Documento final do XVIII Encontro Nacional da Associação Nacional pela Formação dos Profissionais da Educação. Políticas de formação e valorização dos profissionais da educação: conjuntura nacional avanços e retrocessos. Goiânia: Associação Nacional pela Formação dos Profissionais da Educação, 2016.

BAZZO, Vera; SCHEIBE, Leda. De volta para o futuro. Retrocessos na atual política de formação de professores. Retratos da Escola, Brasília, v. 13, n. 27, p. 669-84, set./dez. 2019. Disponível em: http://retratosdaescola.emnuvens.com.br. Acesso em: 3 jun. 2020.

BERNSTEIN, Basil. A estruturação do discurso pedagógico: classe, códigos e controle. Petrópolis: Vozes, 1996.

BRANDÃO, Zaia. A Dialética micro/macro na Sociologia da Educação. Cadernos de Pesquisa, São Paulo, n. 113, p. 153-65, jul. 2001. Disponível em https://www.scielo.br/pdf/. Acesso em: 1으ov. 2019.

BRASIL. Ministério de Educação e do Desporto. Conselho Nacional de Educação. Resolução CNE/CP n. 01/06. Diretrizes Curriculares Nacionais para o Curso de Pedagogia. BrasíliaDF, 2006.

BRASIL. Ministério de Educação e do Desporto. Conselho Nacional de Educação. Parecer CNE/ CP n. 05/05. Diretrizes Curriculares Nacionais para o Curso de Pedagogia. Brasília-DF, 2005. 
BRASIL. Ministério de Educação e do Desporto. Conselho Nacional de Educação. Resolução CNE/CP n. 01/02. Diretrizes Curriculares Nacionais para a Formação de Professores da Educação Básica, em nível superior, curso de licenciatura, de graduação plena. BrasíliaDF, 2002.

BRASIL. Ministério de Educação e do Desporto. Conselho Nacional de Educação. Resolução CNE/CP n. 02/15. Diretrizes Curriculares Nacionais para a formação inicial em nível superior e para a formação continuada. Brasília-DF, 2015.

BRASIL. Ministério de Educação e do Desporto. Conselho Nacional de Educação. Resolução CNE/CP n. 02/17. Base Nacional Comum Curricular. Brasília-DF, 2017.

BRASIL. Ministério de Educação e do Desporto. Conselho Nacional de Educação. Resolução CNE/CP n. 02/19. Diretrizes Curriculares Nacionais para a formação inicial de professores para Educação Básica e institui a Base Nacional Comum para Formação de professores da Educação Básica (BNC-Formação). Brasília-DF, 2019.

CANDAU, Vera Maria Ferrão. A formação de educadores: uma perspectiva multidimensional. In: CANDAU, V. M. F. (Org.). Rumo a uma nova didática. 21. ed. Petrópolis: Vozes, 2011.

CANDAU, Vera Maria Ferrão. Reformas educacionais hoje na América Latina. In: MOREIRA, A. F. B. Currículo políticas e práticas. 13. ed. Campinas: Papirus, 2013.

DIAS, Rosanne Evangelista. Produção de políticas para formação de professores. In: LOPES, A. C.; LOPES, Alice Casimiro, LOPES, Amélia, LEITE, Carlinda, MACEDO, Elizabeth; TURA, Maria de Lourdes (Org.). Políticas educativas e dinâmicas curriculares no Brasil e em Portugal. Petrópolis: DP et Alii; Rio de Janeiro: Faperj, 2008.

DOURADO, Luiz Fernandes. Diretrizes Curriculares Nacionais para a formação inicial e continuada dos profissionais do magistério da educação básica: concepções e desafios. Educação e Sociedade, Campinas, v. 36, n. 131, p. 299-324, jun. 2015. Disponível em: http://www.scielo.br/scielo.php?pid. Acesso em: 3 nov. 2019.

FARIAS, Isabel Maria Sabino. O discurso curricular da proposta para BNC. Retratos da Escola, Brasília, v. 13, n. 25, p. 155-68, jan./maio 2019. Disponível em: http://www.esforce. org.br. Acesso em: 6 nov. 2019.

FREIRE, Paulo. Pedagogia do Oprimido. 17. ed. Rio de Janeiro: Paz e Terra, 1987.

FREITAS, Helena C. Lopes. A (nova) política de formação de professores. Educação e Sociedade, Campinas, v. 28, n. 100 (especial), p. 1203-30, out. 2007. Disponível em: http://www.cedes.unicamp.br. Acesso em: 13 fev. 2018. 
O curso de Pedagogia e os retrocessos na legislação educacional: uma ofensiva às possibilidades de formação crítica

GATTI, Bernadete Angelina; BARRETTO, Elba S. de Sá; ANDRÉ, Marli Eliza Dalmazo de Afonso A. Políticas docentes no Brasil: um estado da arte. Brasília: Unesco, 2011.

GIROUX, Henry. A. Os professores como intelectuais. Porto Alegre: Artmed, 1997.

LOPES, Alice Casimiro. Relação macro/micro na pesquisa em currículo. Cadernos de Pesquisa, v. 36, n. 129, p. 619-35, set./dez. 2006. Disponível em: https://www.scielo.br/ pdf/cp/v36n129/. Acesso em: 1으. nov. 2019.

SANTOS, Boaventura de Sousa. Pela mão de Alice: o social e o político na pós-modernidade. 14. ed. São Paulo: Cortez, 2013.

SCHEIBE, Leda. Formação dos profissionais da educação pós-LDB: vicissitudes e perspectivas. In: VEIGA, I. P. A. AMARAL, A. L. (Org.). Formação de professores: políticas e debates. Campinas: Papirus, 2002.

SCHEIBE, Leda. Diretrizes curriculares de para o curso de Pedagogia: trajetória longa e inconclusa. Cadernos de Pesquisa, v. 37, n. 130, p. 43-62, jan./abr. 2007. Disponível em: https://www.scielo.br/scielo.php?pid. Acesso em: 7 jun. 2019.

SILVA, Katia Augusta P. Curado. A formação de professores na perspectiva críticoemancipadora. Linhas Críticas, Brasília, v. 17, n. 32, p. 13-31, jan./abr. 2011. Disponível em: http://repositorio.unb.br/bitstream/. Acesso em: 2 jan. 2019.

SILVA, Katia Augusta P. Curado. Epistemologia da práxis na formação de professores. Revista de Ciências Humanas - Educação, v. 18, p. 15, 2017. Disponível em: http://revistas.fw.uri. br/index.php/revistadech/article. Acesso em: 3 ago. 2019.

VÁZQUEZ, Adolfo Sánchez. Filosofia da Práxis. 2. ed. São Paulo: Expressão Popular, 2011. VEIGA, IIma Passos Alencastro; VIANA, Cleide Maria Quevedo Quixadá. Formação de professores: um campo de possibilidades inovadoras. In: VEIGA, I. P. A.; SILVA, E. F. da (Org.). A escola mudou. Que mude a formação de professores! 3. ed. Campinas: Papirus, 2012.

\section{Sobre as autoras:}

Antonia Alves Pereira Silva: Doutora em Educação pela Universidade do Estado do Rio de Janeiro (Uerj). Pedagoga. Professora assistente da Universidade Estadual do Piauí (Uespi). Atua e pesquisa na área de Formação de Professores. Membro do Núcleo de Estudos e Pesquisas em Educação e Sociedade (Nepes/ 
Uespi) e do Grupo de Pesquisa Políticas de Avaliação, Desigualdades e Educação Matemática (ProPEd-Uerj). Orcid: https://orcid.org/0000-0003-1146-345X, E-mail: antoniaalves0416@yahoo.com.br

Maria Isabel Ramalho Ortigão: Pós-doutora (Professora Visitante Sênior na Universidade de Lisboa - área Avaliação Educacional (Bolsista Capes-PrInt/ Uerj). Doutora em Educação pela Pontifícia Universidade Católica (PUC-Rio). Graduada em Pedagogia e Matemática. Professora associada da Universidade do Estado do Rio de Janeiro (Uerj). Pesquisadora do CNPq (Pq-2), procientista (Uerj) e cientista do Nosso Estado (Faperj). Atua na área de Políticas de Avaliação. Editora associada de seção da Zetetiké e líder do grupo de pesquisa Políticas de Avaliação, Desigualdades e Educação Matemática (CNPq/ProPEd-Uerj). Orcid: https://orcid.org/0000-0001-7269-592X,E-mail: isabelramalhoortigao@gmail.com

Recebido: 30 de julho de 2020

Última revisão: 17 de agosto de 2020 Aprovado em: 9 de setembro de 2020 